\title{
CONCENTRAÇÃO REGIONAL DO VALOR BRƯTO DA PRODUÇÃO DO ABACAXI NO PARANÁ
}

Luiz Moreira Coelho Junior*

RESUMO: O cultivo de abacaxi é uma alternativa para geração de renda na agricultura paranaense. Em condições subtropicais, com baixo risco de perdas por geadas, é possível realizar plantios comerciais como estratégia de diversificação agrícola. Este artigo analisou o grau de concentração do Valor Bruto da Produção (VBP) do abacaxi no Paraná - entre 1995 e 2010 - por meio dos dados disponíveis do Instituto Paranaense de Desenvolvimento Econômico e Social (Ipardes). O grau de concentração foi determinado por meio da Razão de Concentração [CR(k)], do Índice de Gini (G) e do Índice de Hall-Tideman (HTI). Os resultados mostram que o valor bruto da produção do abacaxi no Paraná apresentou um crescimento médio de $20 \%$ a.a. no período de análise. A razão de concentração dos quatro [CR(4)] e oito maiores $[\mathrm{CR}(8)]$ do VBP do abacaxi paranaense é moderadamente alta para os municípios e alta a muito alta para microrregióes. $\mathrm{O} G$ mostrou movimentos de concentração regional, nos níveis de municípios, microrregiões e mesorregiões, indicando uma desigualdade forte a muito forte para o valor bruto de produção do abacaxi no Paraná. O HTI apresentou movimentos similares aos da razão de concentração com as quatro maiores participações.

PALAVRAS-CHAVE: Fruticultura; Índices de concentração; Economia regional.

\section{REGIONAL CONCENTRATION OF GROSS PRODUCTION VALUE OF PINEAPPLE IN THE STATE OF PARANÁ, BRAZIL}

ABSTRACT: The cultivation of pineapple is an alternative profit earning within the agriculture status of the state of Paraná, Brazil. Commercial planting as a strategy for agricultural diversification is possible in subtropical conditions with low frostcaused losses. Current paper analyzed the concentration degree of the Gross Production Value (GPV) of the pineapple in the state of Paraná between 1995 and 2010 through data from the Instituto Paranaense de Desenvolvimento Econômico e Social (Ipardes). Concentration degree was calculated by the Concentration ratio

\footnotetext{
Universidade Federal da Paraíba, João Pessoa (PB). Centro de Energias Alternativas e Renováveis - CEAR. Docente de Economia de energias renováveis no Departamento de Engenharia de Energias Renováveis - DEER, Brasil. E-mail: luiz@cear.ufpb.br
} 
[CR(k)], Gini's Index (G) and Hall-Tideman Index (HTI). Results reveal that GPR of pineapple in the state of Paraná had a mean growth of $20 \%$ per annum during the period analyzed. Concentration ratio of four $[\mathrm{CR}(4)]$ and eight highest $[\mathrm{CR}(8)]$ of GPR of pineapple was slightly high for the municipalities and between high and very high for micro-regions. G showed shifts in regional concentration, at municipal, microregional and meso-regional levels, indicating a strong to very strong inequality for GPR of pineapple in the state of Paraná. HTI revealed similar shifts to concentration ratio with the four greatest participations.

KEY WORDS: Fruit culture; Concentration index; Regional economy.

\section{INTRODUÇÃO}

O abacaxi Ananas comosus (L) Merril é uma autêntica fruta da América Latina, de regiões tropicais e subtropicais, mais precisamente do Brasil e Paraguai. O abacaxi é consumido mundialmente, tanto in natura quanto na forma industrializada, e sua importância no agronegócio brasileiro vem aumentando a cada ano (MELETTI et al., 2011).

Segundo a Organização das Nações Unidas para Agricultura e Alimento (FAO, 2017), em 2014, a produção mundial de abacaxi foi de 21,06 bilhões de toneladas (t), sendo os principais países Costa Rica 2,92 bi t, Brasil 2,65 bi t, Filipinas 2,51 bi t, Tailândia 1,91 bi t e Indonésia 1,83 bi t que, juntos, representam cerca de 50\% da oferta global de abacaxi.

De acordo com o Instituto Brasileiro de Geografia e Estatística (IBGE, 2017), em 2014, a produção brasileira é destinada basicamente ao mercado doméstico e está nas regiões com 39,53\% no Nordeste, 28,01\% no Sudeste, 25,92\% no Norte, 5,7\% no Centro-Oeste e apenas $0,87 \%$ no Sul. As do Pará com 18,49\%, Paraíba com $18,01 \%$, Minas Gerais com 13,94\% e Bahia com 7,98\% representam cerca de $60 \%$ da produção nacional.

Em condições subtropicais, desde o início da década de 1980, o Instituto Agronômico do Paraná - Iapar - estuda e incentiva o cultivo de abacaxi como alternativa à culturas tradicionais. Em regiões mais quentes do Paraná, com baixo risco de perdas por geadas, é possível realizar plantios comerciais como alternativa 
de renda à agricultura familiar. As variedades de abacaxi que predominam nas condições de clima subtropical são 'Smootb cayenne' (Havaî) e 'Pérola', embora a esta variedade apresente uma pequena participação na produção estadual (CARVALHO; AULER, 2005).

Em 2010, o Paraná apresentou uma área colhida de 404 hectares (ha) no qual se produziram 10.192 t de abacaxi, tendo média de 24,61 t/ha, sendo o Estado o maior produtor de abacaxi no Sul do Brasil. O Estado se encontra no $19^{\circ}$ do ranking nacional, participando apenas de $0,58 \%$ da produção brasileira (IBGE, 2012).

Avelino et al. (2009) e Coelho Junior (2013) destacam que as estratégias de diversificação, principalmente em mercados pouco explorados como o cultivo do abacaxi. promovem o desenvolvimento, sob condições de economias de escala e escopo. Rocha (2010) afirmou que os coeficientes de concentração sintetizam, em um único indicador, um conceito de múltiplas dimensões como oferta e demanda, capacidade tecnológica, estrutura de custos, entre outros.

Contudo não há estudos mostrando a concentração do valor bruto da produção do abacaxi no Estado do Paraná em busca de orientar a tomada de decisão à diversificação na pauta de produção agrícola e a orientação de políticas públicas para promoção do desenvolvimento regional. O objetivo deste trabalho é analisar o grau de concentração do valor bruto da produção do abacaxi no Paraná, no período de 1995-2010.

\section{MATERIAL E MÉTODOS}

Os dados utilizados para determinação da desigualdade do valor bruto da produção de abacaxi no Paraná, no período de 1995 - 2010, foram obtidos junto à base de dados do Estado (BDEweb), do Instituto Paranaense de Desenvolvimento Econômico e Social (Ipardes). Essas informações foram obtidas em nível municipal, microrregional e mesorregional do Paraná.

Para se caracterizar a evolução do valor bruto de produção (VBP) do abacaxi no Paraná, foram considerados os anos de 1995, 1998, 2001, 2004, 2007 e 2010, para mesorregiões paranaenses, classificadas pelo ano de 2010. Para se verificar 
essa evolução, utilizou-se a taxa de crescimento geométrico $\left(r_{g}\right)$, que utiliza as variáveis referentes à produção residente em dois períodos distintos. É expressa em percentual e calculada pela fórmula

$$
r_{g}=\left(\sqrt[n]{\frac{p_{(t+n)}}{p_{(t)}}}\right)-1
$$

em que

$p_{(t)}=$ VBP do abacaxi no período $t$

$p_{(t+n)}=\mathrm{VBP}$ do no período $(t+n)$

$t=$ expresso em ano; $n=$ intervalo de tempo entre essas datas, medido em ano ou fração de ano.

As medidas de concentração e desigualdades utilizadas foram a razão de concentração, o índice de Gini e o índice de Hall-Tideman, descritos a seguir. A razão de concentração $C R(k)$ é um índice que considera a participação no mercado internacional dos $\mathrm{k}$ (sendo $\mathrm{k}=1,2, \ldots, \mathrm{n}$ ) municípios de maiores VBP de abacaxi. Bain (1959) diz que a forma algébrica da razão de concentração é

$$
C R(k)=\sum_{i=1}^{k} s_{i}
$$

em que

$C R(k)=$ Razão de concentração de $k$ maiores municípios de VBP de abacaxi no Paraná;

$s_{i}=$ market share, em porcentagem, do município $i$ de VBP de abacaxi no Paraná.

Convencionalmente, utilizam-se o $\mathrm{CR}(4)$ e o $\mathrm{CR}(8)$ para análise de concentração industrial, pois, à medida que o valor do índice aumenta, eleva-se 
também o poder de mercado virtual dos maiores produtores. A Tabela 1 mostra as classificações para CR(4) e CR(8), segundo Bain (1959):

Tabela 1. Classificação da razão de concentração [CR(k)]

\begin{tabular}{l|cc}
\hline Grau de Concentração & CR (4) & CR(8) \\
\hline Muito Alto & $75 \%$ ou mais & $90 \%$ ou mais \\
Alto & $65 \%-75 \%$ & $85 \%-90 \%$ \\
Moderadamente alto & $50 \%-65 \%$ & $70 \%-85 \%$ \\
Moderadamente baixo & $35 \%-50 \%$ & $45 \%-70 \%$ \\
Baixo & $35 \%$ ou menos & $45 \%$ ou menos \\
\hline
\end{tabular}

Fonte: Bain (1959).

Para o cálculo da razão de concentração, foram utilizadas as participações do VBP de abacaxi dos municípios e das microrregiões do Paraná que foram ordenadas de forma decrescente.

O índice de Gini (G) é uma medida desenvolvida, originalmente, para se medir a desigualdade de renda e pode, também, ser usado para se medir o grau de desigualdade dos VBP do abacaxi nos municípios e regiões do Paraná. O índice é uma ferramenta acessória aos coeficientes de concentração, uma vez que uma concentração elevada implica em uma desigualdade maior. O cálculo do índice é feito, utilizando-se a seguinte expressão:

$$
G=1-\frac{\left[\sum_{i=1}^{n}\left(s_{i j}+s_{i}\right)\right]}{n}
$$

sendo

$n=$ número de municípios de VBP de abacaxi no Paraná;

$s_{i j}=$ participação cumulativa de VBP de abacaxi no Paraná em ordem crescente;

$s_{i}=$ market share, em porcentagem, do município $i$ com VBP do abacaxi no Paraná. 
O índice varia entre 0 e 1 , classificado da seguinte forma: 0,101 - 0,250 desigualdade nula à fraca; 0,251 - 0,500 desigualdade fraca à média; $0,501-0,700$ desigualdade média à forte; 0,701 - 0,900 desigualdade forte à muito forte; 0,900 - 1,000 desigualdade muito forte à absoluta.

$\mathrm{O}$ índice de Hall-Tideman (HTI) é um indicador de desigualdade que considera todos os envolvidos na atividade agrícola, incorporando o número do ranking às participações de cada um. Pode ser expresso como

$$
H T I=\frac{1}{2 \sum_{i=1}^{n}\left(i \cdot s_{i}\right)-1}
$$

em que

$s_{i}=$ market share, em porcentagem, do município $i$ com VBP do abacaxi no Paraná;

$n=$ número de municípios de VBP de abacaxi no Paraná;

$i=$ ordenação do tamanho dos VBP do abacaxi.

A participação de cada VBP do abacaxi recebe peso igual à sua ordem na apuração do índice, e a ênfase passa a ser o número total de VBP do abacaxi estadual. O intervalo do HTI varia entre 1/n e 1 (um), aproximando-se do limite inferior ( $1 / \mathrm{n})$ para um número de municípios de mesmo tamanho (perfeita igualdade) e atingindo 1 (um) no caso do monopólio (desigualdade absoluta).

\section{RESULTADOS E DISCUSSÃO}

A Tabela 2 apresenta a evolução do Valor Bruto da Produção (VBP), em termos correntes, do abacaxi nas mesorregiões do Paraná, no período de 1995 a 2010. O VBP do abacaxi paranaense foi de $\mathrm{R} \$ 549,00 \mathrm{mil}$, em 1995 , para $\mathrm{R} \$ 8.439,00$ mil, em 2010. O VBP paranaense do abacaxi teve um crescimento médio de $20 \%$ a.a., resultado da atuação dos players (mesorregiões), visando à maior inserção na economia estadual, via expansão da cultura do abacaxi. 
Tabela 2. Evolução do Valor Bruto da Produção, em termos correntes, do abacaxi nas mesorregiões do Paraná, no período de 1995 a 2010 (R\$1.000,00)

\begin{tabular}{|c|c|c|c|c|c|c|}
\hline Mesorregiões & 1995 & 1998 & 2001 & 2004 & 2007 & 2010 \\
\hline Noroeste Paranaense & 135 & 1.033 & 1.780 & 2.513 & 4.403 & 5.474 \\
\hline Sudoeste Paranaense & - & 72 & 930 & 845 & 1.104 & 1.654 \\
\hline Norte Pioneiro Paranaense & - & 133 & 352 & 866 & 127 & 615 \\
\hline Oeste Paranaense & - & 116 & 672 & 54 & 107 & 421 \\
\hline Norte Central Paranaense & 384 & 381 & 257 & 242 & 92 & 184 \\
\hline Sudeste Paranaense & - & - & - & - & 72 & 29 \\
\hline $\begin{array}{l}\text { Centro-Ocidental } \\
\text { Paranaense }\end{array}$ & - & - & 23 & 31 & 360 & 25 \\
\hline Centro-Oriental Paranaense & 30 & - & - & 24 & 68 & 25 \\
\hline Centro-Sul Paranaense & - & - & - & - & - & 12 \\
\hline Metropolitana de Curitiba & - & - & 35 & 36 & - & - \\
\hline Estado do Paraná & 549 & 1.735 & 4.049 & 4.611 & 6.333 & 8.439 \\
\hline
\end{tabular}

Fonte: IBGE (2012).

Quanto à distribuição espacial do VBP do abacaxi no Paraná, observam-se mudanças importantes. Em 1995, ano em que se inicia o estudo, eram somente três mesorregióes produtoras de abacaxi e, ao longo do período analisado, as demais mesorregiões foram se incorporando à abacaxicultura estadual. Em 2010, exceto a região metropolitana de Curitiba, 90\% das mesorregiões contribuíram na participação do VBP do abacaxi no Paraná. Observa-se que, no tocante ao VBP do abacaxi, a participação da mesorregião noroeste paranaense se mostra a mais significativa do cenário estadual, gerando, no período de 1995 a 2010, uma taxa geométrica de crescimento de $28 \%$ a.a..

O rápido crescimento da produção se deu no final do século passado, proporcionando taxas de 46,75\% a.a. durante o quadriênio 1995-1998. O VBP do abacaxi chegou à casa dos bilhões de reais visto que, em 1995, o VBP do abacaxi foi de $\mathrm{R} \$ 549$ mil. A expansão da abacaxicultura na mesorregião noroeste foi decorrente ao seu excepcional desempenho no VBP do abacaxi de 97,06\% a.a., nesse quadriênio. 
A mesorregião norte central paranaense permaneceu estagnada e apresentou taxas descrentes (-0,26\% a.a.), perdendo o $1^{\circ}$ lugar no ranking paranaense nesse período.

Em 1998, mesmo com uma tímida participação, ocorreu inserção de players na conjuntura do VBP do abacaxi no Paraná com as mesorregiões do sudoeste, norte pioneiro e oeste paranaense. Consequentemente, verifica-se um salto no VBP do abacaxi no quadriênio 1998-2001, que passou de $\mathrm{R} \$ 1.735,00$ mil, em 1998, para $\mathrm{R} \$ 4.049,00$ mil, em 2001, ajustado a uma taxa de crescimento de 32,64\% a.a., evidência de retomada do crescimento agropecuário, principalmente, alimentar. Esse quadriênio mostra mudanças estruturais da composição do cenário do VBP do abacaxi, afetando sua importância na dinâmica regional, principalmente, nas mesorregiões do sudoeste $(134,63 \%$ a.a.), oeste $(79,60 \%$ a.a.), norte pioneiro (38,32\% a.a.) e noroeste paranaense $(19,89 \%$ a.a. $)$.

Na primeira década do século XXI o crescimento do VBP do abacaxi estadual foi mais modesto, com 8,5\% a.a., no período de 2001-2010, quando comparado com o período todo em estudo, 20\% a.a., no período de 1995-2010. O VBP do abacaxi no Paraná é concentrado na mesorregião noroeste com uma participação média de 58\%, no período de 2001 a 2010. Apesar de o quadriênio 2001-2004 apresentar crescimento de 4,43\% a.a., o qual foi o mais baixo do estudo, pode-se destacar, nesse quadriênio, a expansão dos VBP's das mesorregiões como o norte pioneiro com $35 \%$ a.a., o noroeste com $12,18 \%$ a.a. e o centro-ocidental com $10,46 \%$ a.a.. Por outro lado, a mesorregião oeste teve um decréscimo no VBP de $\mathrm{R} \$ 672,00$ mil para $\mathrm{R} \$ 54,00$ mil, representando uma queda de 56,85\% a.a. nesse intervalo. Essa queda do VBP do abacaxi também aconteceu no sudoeste, porém com menos intensidade $(-3,14 \%$ a.a. $)$.

Para o quadriênio 2004-2007, os números do VBP do abacaxi no Paraná saltam para valores superiores a $\mathrm{R} \$ 5$ milhões, apresentando um aumento de $11,16 \%$ a.a.. Merece destacar que oito das dez mesorregiões participaram do VBP do abacaxi estadual. Recuperaram-se as mesorregiões oeste (25,60\% a.a) e sudoeste ( $9,32 \%$ a.a.) e a expansão da cultura continua no noroeste (20,56 a.a.). Por sua vez, a mesorregião norte central teve uma queda no VBP de $\mathrm{R} \$ 242,00$ mil para $\mathrm{R} \$ 94,00 \mathrm{mil}$, uma propensão negativa de 47,27 a.a.. No quadriênio 2007-2010 houve expansão nas principais mesorregiões produtoras, com crescimento no VBP, e as mesorregiões 
oeste e norte pioneiro se elevaram acima dos $50 \%$ a.a. e as mesorregiões norte central, sudoeste e noroeste VBP foram inferiores a $30 \%$ a.a..

A Figura 1 apresenta as razões de concentração dos municípios e microrregiões que compõem VBP do abacaxi no Estado do Paraná, no período de 1995 a 2010. Ao longo do período de análise, as microrregiões que mais representaram o $C R(4)_{\text {Micro }}$ foram, praticamente, as microrregiões de Paranavaí, Capanema e Umuarama. Os municípios mais representativos do $C R(4)_{\text {Munic }}$ do VBP do abacaxi foram os municípios de Santa Isabel do Ivaí e Capanema e, em alguns períodos, apontam-se os municípios de Santa Mônica, Sertaneja e Atalaia.

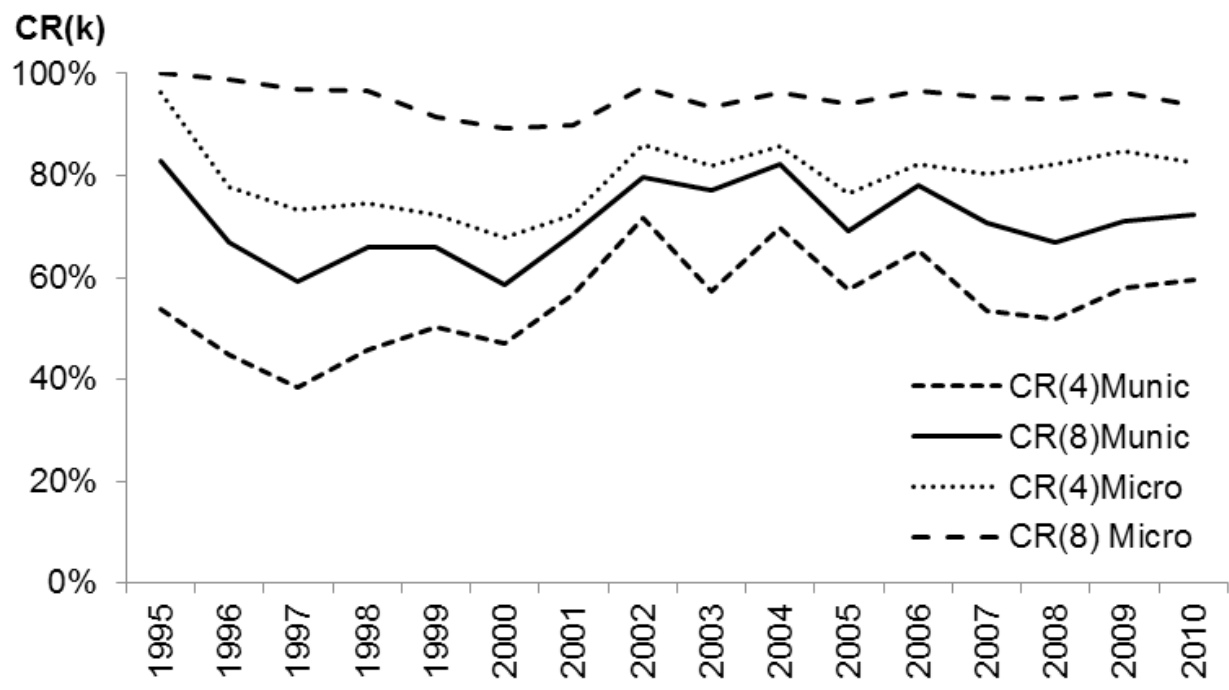

Período

Figura 1. Evolução da (a) Razão de concentração $[C R(k)]$ do VBP do abacaxi no Paraná, para os municípios (Munic) e microrregiões (Micro) 1995 - 2010.

Fonte: Dados da pesquisa.

Seguindo as orientações de Bain (1959), no período 1995-2010, o VBP do abacaxi no Paraná, em nível municipal, apresentou uma estrutura de mercado com concentração moderadamente concentrada. Consequentemente, a Razão de Concentração em nível microrregional tende a ser ainda mais concentrada. O CR(4) Munic do VBP do abacaxi no Paraná variou de 38,50\% a 71,54\%, com média de 55,05\%, indicando um grau de concentração moderadamente baixo a moderadamente alto. 
Observou-se tendência de concentração para moderadamente alto, consolidando-se essa classificação a partir do início do século XXI. Nesse mesmo período, o $C R(8)_{\text {Munic }}$ do VBP do abacaxi variou de $58,71 \%$ a $82,88 \%$, com média de $70,95 \%$, indicando um grau de concentração moderadamente alto.

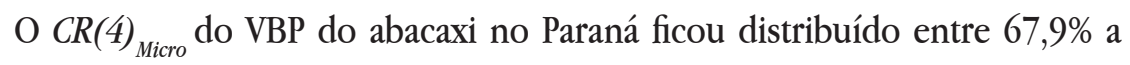
$96,4 \%$, com média de $79,8 \%$, indicando um grau de concentração alto a muito alto, no período 1995-2010. Observou-se tendência de concentração para muito alto, concretizando-se essa classificação do início do século XXI. Nesse mesmo período, O CR(8) $)_{\text {Micro }}$ de VBP do abacaxi no Paraná indicou a variação de 89,34\% a 100\%, com média de 95\%, inferindo um grau de concentração muito alto.

Para Scherer e Ross (1990), quando os quatro municípios e microrregiões maiores produtores detêm mais de $40 \%$ do valor bruto da produção do abacaxi no Estado do Paraná, a estrutura desse mercado é oligopolista. Assim, no período de 1995 a 2010, o VBP do abacaxi apresentou uma estrutura oligoplística de mercado.

A Figura 2 indica que a desigualdade do VBP do abacaxi no Paraná aumentou ao longo do tempo, para os três níveis analisados. À medida que os valores do coeficiente de Gini se aproximam de 1, a desigualdade do VBP do abacaxi no Paraná aumenta.

No período de 1995 a 2010, a desigualdade do VBP do abacaxi no Paraná, por meio das mesorregiões, apresentou maior variação, com $G_{\text {meso }}$ mínimo $(0,215)$ de fraco a médio, $G_{\text {meso }}$ máximo $(0,706)$ de forte a muito forte e $G_{\text {meso }}$ médio $(0,550)$ de médio a forte. Para a desigualdade do VBP do abacaxi no Paraná, por meio das microrregiões, obtiveram-se $G_{\text {micro }}$ mínimo $(0,472)$ de fraco a médio, $G_{\text {micro }}$ máximo $(0,823)$ de forte a muito forte e $G_{\text {micro }}$ médio $(0,719)$ forte a muito forte. Para a desigualdade do VBP do abacaxi no Paraná, por meio dos municípios, mostrouse mais evidente que se obtiveram $G_{\text {munic }}$ mínimo $(0,613)$ de médio a forte, $G_{\text {munic }}$ máximo $(0,856)$ de forte a muito forte e $G_{\text {munic }}$ médio $(0,796)$ de forte a muito forte.

No período 1995-2000, o índice de Gini do VBP do abacaxi no Paraná apresentou elevadas mudanças na classificação para os três níveis estudados $\left(G_{\text {meso' }}\right.$, $G_{\text {micro }}$ e $G_{\text {munic }}$ ), com evidências para uma tendência de desigualdade mais forte. Para o $G_{\text {meso, }}$ passou de uma desigualdade nula à fraca $(0,215)$ para média à forte $(0,548)$. Já o $G_{\text {micro }}$ incidiu em uma desigualdade fraca à média $(0,472)$ para forte à muito 
forte $(0,753)$. E o $G_{\text {munic }}$ sucedeu em uma desigualdade média à forte $(0,613)$ para forte à muito forte $(0,826)$.

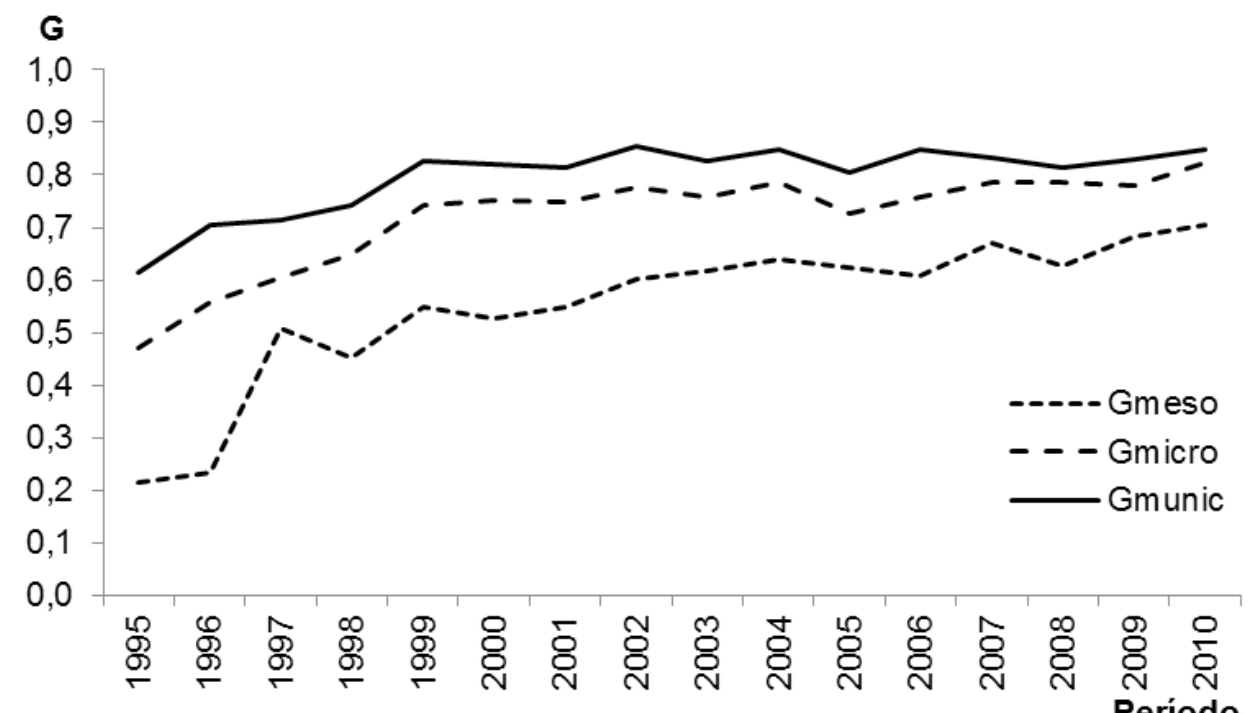

Figura 2. Evolução da (a) Razão de concentração $[C R(k)]$ e do (b) Índice de Gini $(G)$ do VBP do abacaxi no Paraná, para os municípios (Munic) e microrregiões (Micro) e mesorregiões (Meso), $1995-2010$.

Fonte: Dados da pesquisa.

No período de 2001 a 2010, a desigualdade continuou crescente para o VBP do abacaxi no Paraná, mas menos agressiva, quando comparado com o período de 1995 a 2000. Para o $G_{\text {meso, }}$ predominou uma desigualdade média à forte e apenas no ano de 2010 a desigualdade ultrapassou a barreira da desigualdade forte à muito forte. Os $G_{\text {micro }}$ e $G_{\text {munic }}$ apresentaram tendências de aproximação para ambos, com desigualdade forte à muito forte.

A Tabela 3 apresenta os índices de Hall-Tideman (HTI) do VBP do abacaxi no Paraná. A participação de cada componente estudado (municipal, microrregional e mesorregional) recebe peso igual à sua ordem na apuração do índice, e a ênfase passa a ser o número total de integrantes aos níveis representados. Assim, no período de 1995 a 2010, observou-se uma expansão da atividade da abacaxicultura no Paraná, nos diversos níveis apresentados em que o número de participantes foi 
três vezes maior para mesorregião e quatro vezes superior para a microrregião e municípios.

Tabela 3. Índice de Hall-Tideman (HTI), Limite inferior (LI) e número $\left(\mathrm{n}^{\circ}\right)$ de participantes no VBP do abacaxi no Paraná (1995 - 2010)

\begin{tabular}{cccccccccc}
\hline \multirow{2}{*}{ Ano } & \multicolumn{3}{c}{ Mesorregião } & \multicolumn{3}{c}{ Microrregião } & \multicolumn{3}{c}{ Municípios } \\
& HTI & LI & $\mathbf{n}^{\mathbf{0}}$ & HTI & LI & $\mathbf{n}^{\mathbf{0}}$ & HTI & LI & $\mathbf{n}^{\mathbf{0}}$ \\
\hline $\mathbf{1 9 9 5}$ & 0,585 & 0,333 & 3 & 0,439 & 0,200 & 5 & 0,116 & 0,067 & 15 \\
$\mathbf{1 9 9 6}$ & 0,624 & 0,333 & 3 & 0,202 & 0,111 & 9 & 0,071 & 0,034 & 29 \\
$\mathbf{1 9 9 7}$ & 0,519 & 0,200 & 5 & 0,175 & 0,091 & 11 & 0,058 & 0,029 & 35 \\
$\mathbf{1 9 9 8}$ & 0,403 & 0,200 & 5 & 0,184 & 0,083 & 12 & 0,066 & 0,029 & 35 \\
$\mathbf{1 9 9 9}$ & 0,300 & 0,143 & 7 & 0,160 & 0,056 & 18 & 0,051 & 0,015 & 65 \\
$\mathbf{2 0 0 0}$ & 0,275 & 0,143 & 7 & 0,145 & 0,050 & 20 & 0,044 & 0,014 & 72 \\
$\mathbf{2 0 0 1}$ & 0,302 & 0,143 & 7 & 0,167 & 0,056 & 18 & 0,061 & 0,019 & 52 \\
$\mathbf{2 0 0 2}$ & 0,391 & 0,143 & 7 & 0,270 & 0,067 & 15 & 0,090 & 0,020 & 49 \\
$\mathbf{2 0 0 3}$ & 0,256 & 0,111 & 9 & 0,176 & 0,056 & 18 & 0,073 & 0,021 & 48 \\
$\mathbf{2 0 0 4}$ & 0,364 & 0,125 & 8 & 0,234 & 0,059 & 17 & 0,093 & 0,022 & 45 \\
$\mathbf{2 0 0 5}$ & 0,329 & 0,125 & 8 & 0,174 & 0,063 & 16 & 0,063 & 0,021 & 48 \\
$\mathbf{2 0 0 6}$ & 0,400 & 0,143 & 7 & 0,237 & 0,067 & 15 & 0,082 & 0,020 & 50 \\
$\mathbf{2 0 0 7}$ & 0,442 & 0,125 & 8 & 0,233 & 0,059 & 17 & 0,059 & 0,017 & 60 \\
$\mathbf{2 0 0 8}$ & 0,449 & 0,143 & 7 & 0,234 & 0,059 & 17 & 0,059 & 0,019 & 54 \\
$\mathbf{2 0 0 9}$ & 0,480 & 0,125 & 8 & 0,245 & 0,063 & 16 & 0,065 & 0,019 & 54 \\
$\mathbf{2 0 1 0}$ & 0,436 & 0,111 & 9 & 0,226 & 0,048 & 21 & 0,063 & 0,016 & 62 \\
\hline
\end{tabular}

Fonte: Dados da pesquisa.

Realizou-se a diferença dos HTI's e seus respectivos limites inferiores em que se pode inferir tendência no aumento de desigualdade ao longo do tempo para os três níveis estudados. Dos três componentes, o municipal foi o que mostrou menor tendência de desigualdade, seguido das microrregiões, e o mais desigual foram as mesorregiões.

No período de 1995 a 2000, ocorreram movimentos similares entre as mesorregiões e, a partir do século XXI, mostraram-se evidências de desigualdade entre as mesorregiões. Houve oscilações de maior e menor desigualdade entre 2001 e 2006. O HTI dos municípios apresentou-se mais homogêneo, apesar de algumas 
oscilações de maior desigualdade no período de 2000 a 2006. De 2007 em diante houve estagnação na desigualdade.

\section{CONCLUSÕES}

A partir dos resultados e discussão apresentados, conclui-se que

O valor bruto da produção do abacaxi no Paraná é crescente ao longo do tempo com um crescimento médio de $20 \%$ a.a.

As principais participações no valor bruto da produção do abacaxi no Paraná para mesorregiões foram o noroeste, o sudoeste, o norte pioneiro e o oeste, nas microrregiões estavam Paranavaí, Capanema e Umuarama e, nos municípios, Santa Isabel do Ivaí, Capanema, Santa Mônica, Sertaneja e Atalaia.

Segundo a classificação de Bain, a razão de concentração dos quatro e oito maiores produtores do valor bruto de produção é moderadamente alta para os municípios e alta à muito alta para microrregiões.

$\mathrm{O}$ índice de Gini mostrou movimentos crescentes às desigualdades ao longo do período analisado, indicando desigualdade forte à muito forte para o valor bruto de produção do abacaxi no Paraná, em níveis de municípios, microrregiões e mesorregiões. $\mathrm{O}$ índice de Hall-Tideman apresentou movimentos similares aos da razão de concentração com as quatro maiores participações.

\section{REFERÊNCIAS}

AVELINO, G. M. P.; CARVALHO, R. M.; SILVA, L. A. C. O comércio intra-setorial e suas implicações para a economia cearense. Revista de Economia e Sociologia Rural, Brasília. v. 47, n. 4, p. 831-855, 2009. Disponível em: <http://dx.doi.org/10.1590/ S0103-20032009000400002>. Acesso em: 20 set. 2014. DOI: 10.1590/S010320032009000400002.

BAIN, J. Industrial organization. New York: J. Wiley, 1959. 274 p.

CARVALHO, S.L.C.; AULER, P.A.M. Abacaxi: cultivo nas condições subtropicais do Paraná. IAPAR, 2005 (Folder Técnico). 
COELHOJUNIOR, L. M. Concentração regional do valor bruto de produção da banana do Paraná, Brasil (1995 a 2010). Ciência Rural (UFSM. Impresso), v. 43, p. 23042310, 2013. Disponível em: < http://dx.doi.org/10.1590/S0103-84782013005000137 >. Acesso em: 20 mar. 2014. DOI: 10.1590/S0103-84782013005000137

FOOD AND AGRICULTURE ORGANIZATION OF THE UNITED NATIONS (FAO). FAO Statistics Division 2017. Rome, 2010. Disponível em: < http://faostat.fao.org > Acesso em: 15 fev. 2017.

IBGE. INSTITUTO BRASILEIRO DE GEOGRAFIA E ESTATISTICA. SIDRA. Disponível em: <www.sidra.ibge.gov.br/bda/pesquisas/pam/default.asp >. Acesso em: 15 fev. 2017.

MELETTI, L. M. M.; SAMPAIO, A. C.; RUGGIERO, C. Avanços na fruticultura tropical no Brasil. Revista Brasileira de Fruticultura, Jaboticabal, v. 33, n. especial, p. 73-75, 2011. Disponível em: < http://dx.doi.org/10.1590/S0100-29452011000500010>. Acesso em: 15 ago. 2013. DOI: 10.1590/S0100-29452011000500010

ROCHA, F. Dinâmica da concentração de mercado na indústria Brasileira, 19962003. Economia e Sociedade, Campinas, v.19, n.3, p. 477-498, 2010. Disponível em: <www.eco.unicamp.br/docprod/downarq.php?id=721\&tp=a $>$. Acesso em: 20 jul. 2013.

SCHERER, F. M.; ROSS, D. Industrial market structure and economic performance. 3. ed. Boston: Houghton Mifflin, 1990. 270 p.

Recebido em: 28 de outubro de 2015 Aceito em: 22 de fevereiro de 2017 